\title{
MISSION-DRIVEN NEEDS: UNDERSTANDING THE MILITARY RELEVANCE OF SOCIO-CULTURAL CAPABILITIES
}

\author{
P. M. Picucci \\ Susan K. Numrich \\ Institute for Defense Analyses \\ 4850 Mark Center Drive \\ Alexandria, VA 22311, USA
}

\begin{abstract}
The process of translating socio-cultural understanding and models into improved military effectiveness and expanded capabilities often seems sisyphean in its difficulty. This paper describes the clash of cultures that occurs when the deterministic mindset meets non-deterministic models and in which the desire for prediction can only be met by descriptive models. This disjuncture is exacerbated by the fact that the vocabularies, modeling assumptions and data sets that have supported the military modeling and simulation community do not provide adequate bases for the inclusion of social science models. We contend that in such an environment, solutions must be crafted to be specific to missions, areas of operation (geographic regions), levels of command (tactical, strategic, etc.) and operator skill level. By using the above parameters to clarify needs, the community will be better positioned to provide viable solutions supported by available data that can meet the expectations of end users.
\end{abstract}

\section{INTRODUCTION}

DoD recognized the shift from conventional to irregular warfare, as well as the need for the U.S. to lead stabilization, security, transition, and reconstruction efforts globally. These challenges demand a deep and broad understanding of socio-cultural dynamics. (Schmorrow 2009)

For many years the U.S. military research and development enterprise has concentrated its efforts on mathematical, physical, material and engineering sciences with the results of producing excellent weapons systems, platforms (ships, planes, tanks, etc.), command and control systems, sensors and surveillance systems. These capabilities have made the U.S. the global military power in the world. Given that prowess, some of our adversaries have chosen a very different type of engagement, one in which force-on-force battlefield advantage does not play. This adversary is not a national army, but an insurgency or terrorist group that operates within the society and is virtually indistinguishable from the indigenous population. Whether the resultant type of combat is referred to as military operations in urban terrain (MOUT), counterinsurgency (COIN) or irregular warfare (IW), the Irregular Warfare Joint Operating Concept (IWJOC) voiced the change and its implications.

Irregular warfare is about people, not platforms. IW depends not just on our military prowess, but also our understanding of such social dynamics as tribal politics, social networks, religious influences, and cultural mores. People, not platforms and advanced technology, will be the key to IW success. The joint force will need patient, persistent, and culturally savvy people to build the local relationships and partnerships essential to executing IW. (Department of Defense 2007)

The above statement from the Executive Summary is an assertion based on experience rather than a empirical validation and the sentiments contained therein have been echoed in numerous other publications, official and otherwise, published in the Department of Defense (DoD). 


\section{Picucci and Numrich}

However, the push for a socio-cultural capability is not being generated solely from a perceived shift toward irregular warfare. Today's military is increasingly concerned with conflict prevention and the establishment or maintaining of order in states and regions - defined as stability operations. DoD Instruction 3000.05 designates these operations as a "core U.S. military mission that the DoD shall be prepared to conduct with proficiency equivalent to combat operations." (DODI 3000.05 2009). This shift greatly expands the scope of defense strategy and is turning the concept of military threats as strictly adversary-focused on its head. The dynamics of a population are no longer merely elements of the operating environment, they represent potential threats to and opportunities for the enhancement of stability.

The issue of understanding these dynamics must be addressed from every dimension that describes the life of individuals living within a society and their perceptions of that life. Whether the problem is described as winning "hearts and minds," restoring effective governance, or maintaining existing stability, the choice of action and the interplay of socio-economic factors with military force has driven the military to accept, willingly or otherwise, the fact that its job is not only to secure by force, but to hold by providing local security (policing and making sure that justice is dispensed), to build the bridge between the local population and legitimate governance and to identify and respond appropriately to threats-to and opportunities-for the maintenance of stable global relations. If the goal is stability, the exit strategy for our ongoing irregular warfare efforts involves actions that, at the least, plant the seeds for that stability. Outside of those efforts, our continuing strategy involves actions that nurture and protect both nascent and existing stability through the development of lasting partnerships both within and across state boundaries. In either case the tasks exist solidly within the sociocultural domain.

\section{NEEDS, CAPABILITIES AND BENEFITS}

The hard problem of creating capability must start with a dialog between the knowledgeable capability provider and the end user who needs help; however, there is no common language, a wide divergence in methodologies and lack of understanding on both sides. As knowledgeable as the socio-cultural expert might be, he has no clear understanding of the work of the military, its missions or the means available for applying data, information or insight. Having made these distinctions, it is important to note that there are military men and women with deep experience and understanding in socio-cultural domains and likewise, academics and civilian experts with military experience. However, the intersection of these groups is a very small subset

\subsection{Understanding Needs}

While there is limited dialog between the military and the social science community, there have been numerous statements on the part of the military about how they see better understanding of the human domain impacting their missions. From strategic to tactical, whether the domain is intelligence or nation-building, the military have expressed their idea of what socio-cultural understanding would bring to their battlespace or operating domain.

Military roles are distinguished along many lines. This paper considers four of those distinctions. The first is between the various mission types. Missions require different expertise and understanding. To the set tasks we normally associate with the military, the shift in emphasis to irregular warfare and stability operations has brought to the fore a host of other tasks not normally associated with "fighting and winning the nation's wars." The second distinction (area of operation or AO) is drawn from the manner in which the U.S. military are deployed under regional commands and must respond to the peculiar demands of those regions. The problem sets to be addressed by the forces differ widely from region to region as does their need for socio-cultural understanding. The third distinction is levels of command -- strategic, operational, and tactical. For each of these levels, the extent of the geographic play, the timelines for action (immediate to long range) and the planning horizon impact the force structure, the expertise of the force and the nature of the information needed for executing various missions. The final distinction is concerned with the individual operator and the skill he or she brings to that task. These four distinctions (referred to as MALO: Mission, Area of operation, Level of 


\section{Picucci and Numrich}

command, and Operator expertise) are important as we consider the type of socio-cultural information needed as well as the time and expertise available to acquire data and handle complex models.

\subsection{Mission Centric Needs}

Needing to be responsive across the domain of all DoD mission areas presents two seemingly contradictory requirements to the HSCB modeling community. First, although missions differ and scope and granularity as well as objective and means for achieving that objective, there is a fundamental sameness across all missions that is derived from joint doctrine. All missions, no matter what type, or at what level of the strategic to tactical landscape must be coordinated to achieve desired U.S. ends. In the words of GEN McChrystal, "You must understand the mission; understand what we're trying to accomplish - and why." (McChrystal 2009b). This necessitates a degree of interoperability, or, at least, translatability across mission sets within a given area of operation. Fundamental to all operations is acquiring an understanding of the environment in which the engagement will take place.

The conflict in Afghanistan can be viewed as a set of related insurgencies, each of which is a complex system with multiple actors and a vast set of interconnecting relationships among those actors. The most important implication of this view is that no element of the conflict can be viewed in isolation - a change anywhere will affect everything else. This view implies that the system must be understood holistically, and while such understanding is not predictive, it will help to recognize general causal relationships... There are five principal actors in this conflict: the Afghan population, GIRoA, ISAF, the insurgency, and the external players. It is important to begin with an understanding of each of these actors, starting with the most important: the people. (McChrystal Sept. 2009)

\subsubsection{Centrality of Mission (M)}

This need for a comprehensive, unitary picture of the environment is necessarily at odds with the demands of specific missions. The information required to perform a successful key leader engagement with village elders is clearly not the same kind of information necessitated by a Special Operations arrest and detention mission or that of training a local law enforcement unit. Yet each of these missions could very well occur within the same, relatively small, area of operation.

A critical mission for all military is training but even within this singular mission set the needs for HSCB modeling vary. All service components are reworking their school houses and deployed training at both enlisted and officers levels. The need for this was reiterated by Secretary of Defense Gates in May 2010. In a widely circulated memorandum he stated: "To implement the strategy in Afghanistan and Pakistan successfully, U. S. forces and the DoD civilians who support them must be prepared for the operation, geographic, linguistic, and cultural complexities of that environment." (Gates 2010). However this does not imply that the needs of the service components are identical or that different training objectives do not require different capabilities from HSCB modeling. The tools to develop a cultural generalist are very likely not going to be the same tools one would use to develop experts within narrow regional or country specialties.

\subsubsection{Area of Operation (AO)}

Mission needs are also highly dependent upon the operation environment within which the mission takes place. The available sources of socio-cultural information change and the kinds of information needed to perform specific missions shift as does the granularity of that information. Even understanding what those needs are is, in many instances, an open socio-cultural question. Intelligence preparation of the operational environment involves the acquisition of the right type of information and the use of that information to prepare the end users for their specific problem spaces. Responding to disaster relief will be different for a tidal wave in Indonesia and a hurricane in Haiti. Fundamental to all operations is acquiring an understanding of the environment in which the engagement will take place - what is the geography, who are the people, what are their interests and motivations, what capabilities do they have and what are their most urgent needs. The regional combatant command (COCOM) structure of the U.S. military is not merely a matter of organizational convenience. It 


\section{Picucci and Numrich}

evidences a clear understanding that geographic differences also reflect more substantive differences that effect the nature of the U.S. missions within that geographic locale and the ways in which those missions are carried out. Ambassador Robert Loftis, in an interview with Sean McFate, makes it clear that the recent stand-up of U.S. Africa Command (AFRICOM) was partially in recognition that the challenges facing the U.S. military in Africa are different from those in other COCOMs: "Africa is more important to us strategically and deserves to be viewed through its own lens." (McFate 2008).

There is an inherent understanding that a stability operation in U.S. Southern Command (SOUTHCOM) is fundamentally different from the same kind of operation carried out in U.S. Pacific Command (PACOM) or U.S. European Command (EUCOM). DoD maintains regional studies centers (George C. Marshall European Center for Security Studies, Africa Center for Strategic Studies et al) whose tasking includes the development of regional experts and expertise in recognition that this kind of knowledge is not fungible across regional commands. Strategic planning on the part of the regional COCOMs further reflects this understanding by organizing their planning across theater, regional and country level documents. The goals, objectives, and means by which the U.S. engages countries are not merely derived from some classification as ally, neutral, or adversary nor are they dependent entirely upon senior leadership designations with regard to strategic importance. Further, as the following discussion of levels of command will imply, the needed socio-cultural capability is directly linked to the granularity of the area of operation. This is not merely a reiteration that different missions necessitate different needs, it is a recognition that the same mission conducted under different conditions alters the kinds of information needed and potentially the means by which it is collected. Even within the same country, these differences can be stark. Regional variations of population, language, religion, access to technology, etc. impact both the kinds of missions performed and how they are executed. This creates a tremendous challenge to articulation of military needs within the socio-cultural arena as those needs must either be generalizable across a wide variety of areas of operation (potentially limiting the quality of insights that can be gained) or specifically tailored to a geographic or demographic theater (creating enormous costs in start-up time and reach back effort).

\subsubsection{Level of Command}

At the strategic level, DoD is concerned about stability and building sustainable partnerships with the neighboring nations. The focus is long range with an acknowledgement that many of the activities supporting his goals will unfold across a period of years. Admiral Stavridis who recently assumed command of EUCOM and whose role is the sustainment of peace in his region by continuous engagement with the leaders of the nations in his area of operation, chooses to express his vision and concerns in his blog. His concern is at the level of nations within his region and only rarely does it extend below into local and provincial concerns. His concerns are with leaders at national and international levels in government and industry across all the nations of Europe. In his assessment, his ability to maintain a stable security environment depends upon a comprehensive approach that requires both military and socio-cultural skills.

In the end we will never fully deliver security from the barrel of a gun; not in Afghanistan nor anywhere else. It will come as a combination of the so-called "3Ds"-Defense, Diplomacy, and Development. I say it is even broader than that, and will require political, economic, cultural, linguistic, military skills - in simplest terms, combining international, interagency, and private-public approaches. (Stavridis 2010)

For long range planning, for problems of regional, international and global scope, Stavridis clearly states that socio-cultural understanding, the ability to function across cultural groups at a diplomatic level and facility in engaging all pillars of national policy in a well-considered, structured fashion form the framework for a sustainable peace.

The operational level exists in both peace time and during combat, whenever specific activities are needed to support the national security policy. This level of command links strategic objectives to tactical missions. There exists therefore a need for metrics that cross multiple mission sets as well as an ability to tailor mission packages to address desired U.S. ends. In many cases, the operational level of command serves as an essential link between the strategic and tactical - filling in the planning and execution space between the very long 


\section{Picucci and Numrich}

range, multi-national perspective and the minute-to-minute, highly localized focus of the forward command. Developing plans, assessing alternative courses of actions, determining appropriate mix of missions and assigning necessary resources to those missions are part of the work of an operational command. These actions are done very rapidly at the tactical level, but at the operational level time and resources are devoted to creating national and sub-national assessments and plans all of which require socio-cultural, political and economic understanding.

The tactical level of command is most often carried out by the forward operating forces. They are in the midst of the situation and need to make decisions rapidly with whatever tools and information they have on site. The rarely have broadband communication capabilities or reach-back cells capable of responding within necessary timelines. The situation could be counterinsurgency or disaster relief or reconstruction in an area that is only minimally secured. Like the operational commander, those in a tactical position need to know as much as possible about their environment and the other actors - all the other actors. In many cases, they are the best sources of information about "ground truth" in their assigned areas but lack the means for interpreting and transferring relevant elements of that information back up the chain of command. The tactical commander has needs that are often not met by traditional information sources where the expertise is more attuned to actions at the strategic and operational levels. The tactical commander's needs are significantly more concerned with questions of how missions should be executed and whom they should be directed at. The comment below is from a Battalion Commander in Iraq.

I had perfect situational awareness. What I lacked was cultural awareness. I knew where every enemy tank was dug in on the outskirts of Talil. Only problem was my soldiers had to fight fanatics charging in pickups and firing AK 47s and RPGs. Great technical intelligence. Wrong enemy. (Israel 2004).

The tools and information provided to that tactical commander in 2004 were still oriented toward a forceon-force engagement, not to a situation in which the enemy is nearly indistinguishable from the local population let alone situations that lack a traditionally identifiable adversary. At the tactical level, GEN Chiarelli noted that the "strategic corporal" is a reality (Williams 2008). However the notion that in the local engagement, uninformed decisions made by the small unit leader can have dramatic and long range effects was made as early as 1999 by GEN Krulak in his article on the strategic corporal (Krulak 1999). The need for appropriate, culturally attuned information is as important at the tactical level where the soldier at the check point is responsible for immediate decisions as it is for the combatant commander.

From the strategic corporal who must act immediately on minimal information to the combatant commander with the best resources available and who is responsible for the long term security of his part of the world, the modern warfighter needs the best possible information about all the militarily relevant actors in his or her area of operations and the tools for interpreting, working with and disseminating that information.

\subsubsection{Operator Expertise/Proficiency}

Adding to the challenges facing DoD's development and deployment of socio-cultural capabilities embodied in tools is the diverse range of expertise and training of the individuals that will be making use of those tools. In most instances positions are filled by individuals with little or no cultural background in the area they are responsible for or operating in. Until recently emphasis on cultural understanding and cross-cultural awareness was largely absent from doctrinal sources and consequently from most professional military education (PME) (Fawcett 2009). Further, DoD has no mechanism for tracking regional or country expertise in its servicemen and women and therefore no means of ensuring that those personnel that do have relevant expertise wind up in assignments where that knowledge can be put to use. This is compounded by the limitations imposed by assignment rotation. Tours of duty are, in terms of the time needed to develop meaningful cultural awareness, short. Would be operators are saddled with very high learning curves brought on by the lack of means for generating and keeping institutional knowledge. Frequently these issues are coupled with a lack of buy-in to the value added by awareness of the socio-cultural terrain. It is one thing to train into a new recruit the importance of socio-cultural knowledge, it is often quite another to impress upon seasoned veterans the necessity for the inclusion of this knowledge into tasks and processes they have been performing for years. 


\section{Picucci and Numrich}

However, the true challenge is not the provision of tools to those with limited skills in this field but rather the provision of tools useful to a wide range of expertise levels. DoD has begun several efforts to develop cross-cultural awareness within the general-purpose forces and make the necessary changes to PME to sustain those efforts (Fawcett 2009).This implies, however, that this training has not yet had the time to percolate through the entirety of the force presenting DoD with a variety of differing comfort and expertise levels in the socio-cultural field. At the same time exposure to the socio-cultural heavy conflicts in Iraq and Afghanistan create experiential learning of widely varying utility. Additionally, due to the dynamics of the environment experiential learning across tours of duty is not necessarily cumulative and may be contradictory. The military does have a limited cadre of personnel that because of their occupational specialties are highly skilled in their use of socio-cultural tools. What this means is that the set of tools available to any given individual (a country desk officer for instance) must be useful regardless of whether that position is staffed by a career FAO with multiple tours of duty in country or by an F-15 pilot serving his first tour of duty outside of the United States.

\subsection{The Quest for Capabilities}

The capabilities for understanding human dynamics lie at the nexus of multiple disciplines, each of which has different histories, unique terminologies, specialized methodologies and evaluation approaches. These disciplinary differences are in themselves cultural divisions that present a confusing palette of possibilities to the warfighter. Somehow the DoD scientific and technical community must turn its attention to bridging these disciplinary divisions as well as bringing the social science community into effective dialog with the military operators. Confounding these needs are such fundamental problems as lack of common expectations, lack of common vocabulary, lack of appreciation for different scientific approaches and lack of understanding of the data and information needed to support the development of mission-oriented socio-cultural capabilities.

In 2006 in response to a query on the state of capability in DoD for understanding and modeling human dynamics, the Director for Defense Research and Engineering (DDR\&E) evaluated current programs and capabilities and concluded that there were fundamental gaps in two areas: investment and governance. The current Human, Social and Cultural Behavior (HSCB) Modeling program run out of DDR\&E addresses the first of those two gaps, but does not address the second. In addition to the DDR\&E investment, DoD has worked with the National Science Foundation to introduce the MINERVA program and each of the Services has responded to the need with its own efforts. Three years later, the Defense Science Board acknowledged the increased investment, but echoed the lack of coordination and overall governance. It went on to state that there was a no single identified source for identifying all on-going efforts in the study of human dynamics and that to all appearances the existing efforts were "uneven and duplicative, and lack evaluative measure or even common vocabulary." (Defense Science Board 2009).

While capabilities are gradually developing, most notably in the area of social network analysis, needs remain in all mission areas and at all levels of command. Data, understanding and tools are needed in intelligence and operational planning, for stability, security, transition and reconstruction (SSTR), for counterinsurgency and counterterrorism and across every phase of military operations. Models and simulations, strategies for incorporating socio-cultural effects into existing simulations, viable methods for assessing socio-cultural models and effective methods of reducing socio-cultural data into a form that can be used in models and other tools remain challenges to the scientific and technical community.

\subsection{Conceptualizing Benefits}

The needs and desired capabilities expressed above are based upon the assertion that theories, models, simulations and tools developed by the social science research community are able to either generate new capabilities for the U.S. military or provide them with aids to their existing skill sets. While this may seem self-evident to those coming from the social science fields, there exist significant misunderstandings of the nature of benefits that can arise from those fields. DoD is accustomed to the surety inherent in models of the material sciences: probabilistic statements of causality leading to deterministic models able to be tested through a rigorous verification, validation and accreditation (VV\&A) process. The social sciences, while making use of some tools 


\section{Picucci and Numrich}

akin to those used in the hard sciences, deal with a fundamentally different type of knowledge - one that is not reducible down to the kinds of simplified laws and causal statements that characterize the hard sciences. In most instances causality can only be inferred from deep qualitative analysis or from process analysis of correlative relationships. There is no question that the social sciences have advanced our knowledge of the human condition but the question facing DoD's socio-cultural programs is whether that knowledge can be tranformed into tools able to support the missions of the U.S. military.

While it is clear from their statements that senior military personnel believe in the utility or potential utility of these programs, successful application of socio-cultural knowledge is usually articulated via anecdotes in which a crucial socio-cultural factor is presumed to have impeded or enabled DoD operations. Frequently this is done in an ex post facto manner; if only the military had had a particular insight it would have been able to avoid a particularly costly mistake. One oft-repeated anecdote is the story of a non-governmental organization that constructed well only to have it destroyed by the women in an Afghan village because it deprived them of their social gathering time (Flynn et al 2010). Its repetition implies two potentially false conclusions: that this incident is generalizable but more importantly that this insight could have been derived ahead of time through some socio-cultural model or simulation.

What therefore can the military realistically expect as contributions from the social sciences? Three broad areas were identified at the Office of Naval Research Workshop on Operational Applications for Social and Behavioral Sciences and Modeling held in 2008:

- Develop an operationally relevant cultural knowledge base

- Build expeditionary models and data bases for cross-cultural awareness

- Create crisis response and persistent presence training capacity. (Numrich 2008)

The first of these is gives rise to the problem of establishing what is and is not "operationally relevant" within the realm of all possible socio-cultural information. This presupposes that it is possible to define operational relevance across all missions, areas of command, levels of operation, and operators and that agreement on the same can be reached across academic disciplines as well as between the military and social science researchers. However, as indicated in the proceedings from this workshop, the military and social science community must be willing to work together to develop definitions of relevance even if "the definitions are only provisional and subject to change as both the dialog and experience mature."(Numrich 2008) As the dialog continues it seems apparent that a more obtainable benefit is the ability of social science techniques to contribute to prioritization of socio-cultural data particularly with respect to mission, area of operation, and level of command. In this respect the divergence of theoretical perspectives both within and across disciplines may actually prove beneficial. Take, for example, the long contentious debate within political science with regard to causation of social revolution (Lichbach 1999). The models and theories relating to the collective action advocates are likely more relevant to operational and tactical concerns while the work of structural and systemic theorists is likely more relevant at the strategic level. This argues against attempting to marry divergent models and approaches but rather linking those differences to existing differences in needs.

The second area of presumed benefit centers around the transformation of both new and existing social science approaches into fieldable capabilities. Fieldability refers to whether the warfighter, not the technical expert, can employ these capabilities across missions, areas of operation, levels of command, and with the normal skills expected of an operator. Fieldability levies specific requirements on the development of data: that there be shared data structures as well as automated means of ingestion and conversion from unstructured to structured data. For models, fieldability presumes that social science models rest upon causal relationships that can be transparently displayed to operators and that these relationships can be combined meaningfully across models and disciplines. It presupposes that social interactions are dominated by deterministic relationships when, in fact, the vast majority of computation social science models are descriptive in nature and are used to demonstrate that the socio-cultural data under analysis do, in fact, contribute to perceived social behaviors. 


\section{Picucci and Numrich}

How, then, can these descriptive models benefit the warfighter who expects to use causal models? Social scientists are experts at the application of structure to unstructured data. The outcome might be a qualitative narrative that makes sense of an extensive ethnographic collection effort, the translation of a catalogue of events into quantitative measures suitable for statistical analyses, or the use of content analysis to derive comparable estimates of perceptions and decision-making styles. The tools and skill sets associated with these capabilities are directly applicable to military efforts to understand their operational environments and facilitate the visualization of that data into MALO-specific representations. Social science models can be predictive based on pattern recognition and presumed causal correlations but not to the extent that non-behavioral models are. To our knowledge, no behavioral models exist that can predict exact outcomes of actions, nor are such models likely to be developed. It may well be that the primary benefits lie therefore in the areas of prioritization (devote greater resources to missions, areas, and information types that match specific data patterns that are correlated with previously identified threats or opportunities) and awareness (identification of potential second- and third-order consequences of courses of action and anticipation of likely outcomes of those courses).

The final area emphasizes making use of technological solutions to infuse socio-cultural understanding into military training capabilities and again, expectations of benefits may exceed the what social science can provide. Certainly the social sciences are capable of developing training aids for culturally specific scenarios and these can assist in the development of cultural awareness however the true benefit may be far more subtle. Models and simulations may not be able to provide the necessary training to successfully conduct socioculturally informed mission sets but they can facilitate exposure to a variety of differing socio-cultural experiences. Doing so demonstrates the importance of cross-cultural awareness as the undertaking of similar actions across differing socio-cultural terrains results in differing outcomes. Familiarity with the kinds of models employed by social scientists develops an appreciation for the complexity of the socio-cultural environment and therefore inculcates an understanding for both the capabilities and limitations involved in the understanding of human behaviors.

\section{USING MALO-BASED NEEDS TO ADDRESS THE PROBLEM WITH DATA}

Attempting to find the appropriate data to bring understanding to a socio-cultural issue is akin to starving in a land of plenty. While there is a wealth of data to be mined, gathering the data from the multiple sources and then extracting from those sources the specific pieces that are valuable for their military relevance, in a form usable by models and tools, is a gargantuan effort. A more detailed account of the problems of acquiring and managing the right data can be found in the second section of a report by Hurley et al. (2009) .

The first issue that must be addressed is what constitutes data. For many academics and intelligence analysts, data means a set of documents containing information about subjects of interest. These documents could be from text books (history, anthropology, political science, etc.), from research journals, from media reports, from blogs or wikis, literally from any form of publication. They are typically in the form of unstructured text - no tables of data, no spreadsheets or databases - just text. For human users, text is fine; however, for models and other computer-based tools, text is just not data. Data for such applications is a collection of bits in a predetermined configuration that can be accessed and manipulated by computer programs. Thus, one of the most significant problems in socio-cultural understanding is creating usable data from unstructured text. This process involves developing code books where the code describes each datum that is to be logged and its precise meaning as well as the criteria its selection. While computer assisted coding technologies do exist, like the codebooks they are specialized to their particular problem sets.

The most important implication of this view of socio-cultural data is that one cannot provide the warfighter with a tool that requires a great deal of data collection and interpretation. While social scientists are adept at data interpretation, the warfighter has a full-time job and does not come equipped with the tradecraft of a social scientist. As a consequence, one of the first issues for the scientific community is to reduce the data acquisition and interpretation problem.

One of the benefits of approaching socio-cultural understanding and modeling from the perspective of the military mission is that one is then able to reduce the size and scope of the problem, and in so doing limit the 


\section{Picucci and Numrich}

amount of data that must be collected and managed. The military does not need to know everything about a society or groups within a society - only those factors that impact the military mission.

The different levels of command each require different granularity of information. Strategic planners concern themselves with nation-state stability, often assessed from using national statistical tables. One might expect this type of information to be readily available, but while nearly all nations publish national statistical tables, the definition of terms and the algorithms used to compute them are sadly not universal. At the operational level, as evidenced by MG Flynn's approach in Afghanistan, there is need for information below the national level. For countries at risk, there is often little or no reliable data available below the national level. For the tactical commander, the only data he or she will have at the district or village level is what is gathered in the field and that implies that the squad or platoon on the street will have to understand what needs to be acquired and how to go about getting it.

The nature of information available differs from one regional combatant command to another. The countries in EUCOM are well-established with a long history of literacy. There is a good chance that the United States has translation capability both human- and machine-based, for most of the relevant languages. Under such conditions, the potential of acquiring information, both statistical and contextual, down to provincial and sub-provincial levels is excellent. While extraction of machine-usable data from text remains a problem, the reliability of the information in the unstructured text is reasonably good. Contrast that with the new nation states in AFRICOM. Literacy is low. There are few nations with a long history of stability capable of gathering and producing statistical tables even at the national level. And yet, it is far more likely that the United States would be engaged in combat or SSTR activities in African countries where data acquisition is difficult rather than in Europe where usable data is far more plentiful.

The data issue places additional stress on the models developed for socio-cultural understanding. Given that in some cases the data will be uncertain or sparse, socio-cultural models will have to be tested for validity under conditions of sparse, uncertain or missing data. The uncertainty in model results due to the unreliable data conditions is difficult to display for a user even in traditional physics-based models. This implies that the expertise and understanding of the user must be greater for socio-cultural models than for physics-based models until the scientific researchers are better able to display uncertainties in ways that are intuitively understandable for the end-user.

The case we are building is the following. By parsing the larger problem of socio-cultural understanding and modeling along lines of mission, AO, level of command and operator's skill, the issues of data as well as those of modeling can be managed more readily. Data acquisition can be focused, locally oriented data collection strategies can be developed and tools aimed at a particular problem set can be devised without having to solve them as a universal problem.

Another issue in the use of data is the collection of opinion or perceptual data. DoD is far less familiar with this type of data than are other communities. In all operations where the population is the focus, the reaction of the population to their circumstances, to their government, to insurgents and to U.S. and allied forces is critically important. The actual conditions are less important than the population's view of them. Culture and experience play a key role in perceptions. As an example, consider the factual report of having reliable electric power for four hours every day. In many nations this might be cause for celebration, but in Brooklyn, it would likely lead to demonstrations and riots.

Perceptual data is hard to acquire reliably. People will often tell you what they think you want to know either because they are afraid or they just want you to leave them alone. Questions have to be phrased in a culturally perceptive fashion so that the response you get is to what you really want to know. The use of subject matter experts and expatriates is rife with problems as these individuals will have distinct biases and agendas. But the reaction of the population is the most important factor in assessing courses of action in the majority of operations.

One issue that is not as readily managed is the development of a common framework to enable effective storage, manipulation and dissemination of data. Taxonomies are hotly argued issues even within communities that are closely linked culturally and intellectually. We have already noted that understanding human dynamics lies at the nexus of disciplines with very different methods, vocabularies and perspectives. It is likely the use of 


\section{Picucci and Numrich}

multiple taxonomies will be necessary (either as a prelude to the development of an effective framework for socio-cultural information management or as an endstate).

\section{USING MALO-BASED NEEDS TO ADDRESS MODELING CONCERNS}

Modeling concerns center around several basic issues, each of which is informed by correct interpretation of military needs based on the MALO construct. One of these issues is the expressed need for prescriptive models. Partially addressed earlier, it is important to reiterate that truly prescriptive models of the type the military is used to (generation of firing solutions, aircraft load distributions etc.) are simply a "bridge too far" for the behavioral sciences. Human behavior is rarely governed by knowable causal relationships and is subject to far greater apparent randomness based on the staggering number of potentially correlated socio-cultural as well as physical factors that impact decision-making. This need not imply that behavioral modeling is not useful to the military. It does mean that a change must occur in how benefit is perceived.

Understanding what models (or kinds of models) are most useful and how to employ those models is crucial to deriving benefit from socio-cultural modeling and simulation efforts. To that end we propose that the models be evaluated according to their fit across the MALO needs structure. Specification across these factors allows the military to determine the kinds of modeling approaches that best serve their needs; understanding that because needs vary across these factors, a one approach fits-all mentality is fundamentally flawed. Models with high levels of generalizability across the mission, area, and level domains are more appropriately considered tools and will, most often, require users with high degrees of expertise to generate useful end products. Social network analysis tools, which have proliferated within military circles, are symptomatic of this. In most instances it is a relatively simple task to generate a social network map from available data; however, interpretation of that network in ways that are useful to specific missions and specific levels of command requires operators with considerable understanding not only of socio-cultural factors but also of the specific mission sets in question. It is also worth noting that while the development of the social network itself is not difficult if the right data is available, the required data and how one might obtain it are highly area specific.

Comprised of distinct communities with their own jargons and particular methodological biases and constrained by trying to model behaviors which are inherently non-deterministic and multi- (if not non-) causal, social science modeling has generated innumerable behavioral models across the gamut of human behaviors at every level of aggregation (individual, group, state, system). Solid explanatory models do exist for much, if not all, of the behaviors of interest to DoD; however, they exist across multiple disciplines and are often composed from competing if not outright contradictory theoretical propositions. The most common approach to addressing the vast array of models is the push for the development of hybrid and multi-disciplinary models. Evocative of systems-of-systems approaches, these efforts can be quite powerful but are still constrained by mission, area, level and operator domains. Because most of the relationships modeled are correlative rather than causative, contradicting theories can be equally supported by existing data which makes traditional VV\&A methods limited in their utility.

How then is the military to determine which models to incorporate within their desired multidisciplinary frameworks? The answer is complicated by the fact that the appropriate model interactions are likely to require adaptation to a specific area of operation. This is not merely an issue of calibration; relationships between models that existed in one AO may simply not be valid within another. Hybrid systems can partially address this concern. In these frameworks different models are used depending on both the kind of data desired (ie: mission or level of command specificity) or specific conditions dictated by ingested data (ie: area of operation specific). Considerable work has already been done at the strategic level in the development of these kinds of models (notably the DARPA ICEWS project) which, while not truly predictive are nonetheless quite capable of providing significant guidance as to potential "hot spots," thus enabling more efficient resource allocation within given areas of operation (Kettler 2009).

Unfortunately success at the strategic level of command does not ensure success at other levels. Application of these same processes below the strategic level is made more difficult by the needs of those levels which require higher degrees of transparency. At these levels mission sets and courses of action are generated and assessed and this necessitates being able to display the specific factors that gave rise to predicted outcomes. 


\section{Picucci and Numrich}

Without this kind of transparency it is impossible to interact with those factors in order to accentuate or diminish their impacts as desired. It may be that the solution lies with packages of competing models, each transparent in its own right that commanders at the operational level can make use of depending on their sense of appropriateness to their operational environment and objectives. However, this again requires a significant degree of expertise and understanding of these models, otherwise this process may well degenerate to fixation on particular models that appeal not because of their appropriateness but because of familiarity or past performance in other areas and for other missions

\section{CONCLUSION}

Warfighters across all mission areas, at different levels of command and in all regions of the world have expressed a need for more socio-cultural understanding, And it is certainly true that social science can be brought to bear on the vexing problems faced not only in irregular warfare, but in all military missions including disaster relief and in SSTR efforts. There remains a problem of aligning actual capability with expectations. Attempting to solve all the problems at once with a single or even federated set of models and tools is too hard and apt to lead to a failure that could halt real progress. By parsing the problem space into pieces that have natural bounds in content and scope, both the military and scientific community could engage in the type of productive problem solving that should lead to a more unified solution. We have made a case for parsing the problem space along the lines of mission types, areas of operation, levels of command and operator expertise. These divisions would make sense to the military user and open the opportunity for engaging in meaningful dialog among the diverse communities, each of which has a potential part of the puzzle.

\section{REFERENCES}

Defense Science Board Summer Study. 2004. Transition to and from Hostilities. Available via <http://www.acq.osd.mil/dsb/reports/ADA430116.pdf > [accessed June 8, 2010].

Defense Science Board. 2009. Understanding Human Dynamics. Available via <http://www.acq. osd.mil/dsb/reports/ADA 495025 .pdf> [accessed June 10, 2010].

Fawcett, G.S. 2009. Cultural Understanding in Counterinsurgency: Analysis of the Human Terrain System. School of Advanced Military Studies, Fort Leavenworth, KS. Available via <http://www.dtic.mil/cgi-in/GetTRDoc?AD=ADA505497\&Location= $\mathrm{U} 2 \&$ doc $=$ Get TRDoc $\cdot$ pdf $>$ [accessed June 10, 2009].

Flynn, M.T., M. Pottinger, and P.D. Batchelor. 2010. Fixing Intel: A Blueprint for Making Intelligence Relevant in Afghanistan, Voices from the Field. Center for a New American Security. Available via < http: //www. cnas. org/node/3924> [accessed June 10, 2010].

Gates, R.M. 2010. Memorandum for Secretaries of the Military Departments, Chairman of the Joint Chiefs of Staff, Under Secretaries of Defense, Commanders of the Combatant Commands, Commander U.S. Forces Afghanistan, General Counsel of the Department of Defense, Director Cost Assessment and program Evaluation, Directors of Defense Agencies; Subject: Implementing Counterinsurgency (COIN) Training Guidance to Support Execution of the President's Afghanistan-Pakistan Strategy.

Hurley, W. J., C.R. Bucher, S.K. Numrich, S.M. Ouellette, and J.B. Resnick. 2009. Non-Kinetic Capabilities for Irregular Warfare: Four Case Studies. Institute for Defense Analyses Paper P-4436.

Israel, S. and R. Scales. 2004. Iraq Proves It: Military Needs Better Intel. In New York Daily News, January 7 , 2004. Quoted in McFate, Montgomery. 2005. The Military Utility of Understanding Adversary Culture. Joint Force Quarterly. July. Accessible via <http://www. thefreelibrary.com/The+military+utility+of+understanding+ adversary+culture. (Forum) - a0135338796> [accessed June 9, 2010].

Kettler, B. 2009. Mixed Methods Stability Forecasting and Mitigation for the DARPA ICEWS Program. Third International Conference on Computational Cultural Dynamics (ICCCD 2009). Available via <http://www.atl.external. Imco.com/papers/1801.pdf > [accessed June 11, 2010]. 


\section{Picucci and Numrich}

Krulak, C. 1999. The Strategic Corporal: Leadership in the Three Block War. Marines Magazine, January. Available via <http://www.au.af.mil/au/awc/awcgate/usmc/ strategic_corporal.htm> [accessed June 10, 2010].

Lichbach, M.I. 1998. Contending Theories of Contentious politics and the Structure-Action Problem of Social Order. Annual Review of Political Science. Vol 1: 401-424.

McChrystal, S. 2009a. COMISAF Initial Assessment (unclassified). Washington Post. September 21, 2009. Accessible via <http://www.washingtonpost.com/wp-dyn/content/ article/2009/09/21/AR2009092100110.html> [accessed June 9, 2010].

McChrystal, S. 2009b Memorandum dated 10 November 2009, Subject: COMISAF/USFOR-A "Counterinsurgency (COIN) Training Guidance" via <http://usacac.army.mil/CAC2/ coin/repository/COMISAF_COIN_Training_Guidance.pdf> [accessed June 10, 2010]

McFate, S. 2008. U.S. Africa Command: A New Strategic Paradigm? Military Review, January-February 2008, p10.

Numrich, S.K. 2008. Operational Applications for Social and Behavioral Sciences and Modeling. report from the proceedings of a workshop held by the Office of Naval Research in October, 2008

Scales, R.H. 2004. "Culture-Centric Warfare", The Naval Institute: Proceedings, 130(9), p3.

Schmorrow, D. 2009. Q\&A: CDR Dylan Schmorrow. HSCB Newsletter, Issue No. 2, Summer 2009, p5 via < http://home. comcast. net/ dshartley3/DIMEPMESIIGroup/HSCB Newsletter Issue Summer 2009.pdf $>$ [accessed June 10, 2010]

Stavridis, J. 2010. A Global Force for Good. In From the Bridge, Commander's Blog (Feb. 9, 2010) <http://www. eucom.mil/english/bridge/blog. sap > [accessed June 9, 2010 via archives]

United States Department of Defense. 2009. United States Department of Defense Instruction 3000.05 Stability Operations. Available via <http://www.dtic.mil/whs/directives/ corres/pdf / $300005 p$. pdf > [accessed June 10, 2010].

United States Department of Defense. 2007. Irregular Warfare (IW) Joint Operating Concept (JOC). V1.0. Available via < http://www.michaelyon-online.com/images/pdf/iw-joc.pdf> [accessed June 8, 2010].

Williams, M. 2008. Chiarelli to Scientists: Empower 'strategic corporal'. In News Front Page, Dec. 3. 2008) via <http://www.army.mil/-news/2008/12/03/14752-chiarelli-to-scientistsempower-strategic-corporal/> [accessed June 10, 2010]

\section{AUTHOR BIOGRAPHIES}

P.M. PICUCCI is a Research Staff Member for the Joint Advanced Warfighter Division of the Institute for Defense Analyses. He holds a Masters in National Security Studies from California State University, San Bernardino and a Doctorate in Political Science from the University of Kansas. His primary research efforts have centered around non-traditional conflict (irregular warfare and terrorism) and the use of computerized content analysis for the study of Islamic terrorism. His email address is ppicucci@ida.org $>$.

SUSAN K. NUMRICH holds an $\mathrm{AB}, \mathrm{MA}$ and $\mathrm{PhD}$ in physics and worked as a research physicist at the Naval Research Laboratory plying her trade in a variety of fields including underwater sound in the Arctic (yes, aboard ship), fluid-structure interactions, parallel processing, modeling and simulation and virtual reality. Upon leaving government service, Dr. Numrich joined IDA where her work includes studies in irregular warfare, the impact of cultural awareness on military operations, culturally "aware" modeling and simulation tools, data acquisition and sharing, and the potential uses of participatory media (games and beyond). Her email address is <snumricheida. org $>$. 